\title{
Multiple genetic lineages challenge the monospecific status of the West African endemic frog family Odontobatrachidae
}

\author{
Michael F Barej ${ }^{1 *}$, Johannes Penner ${ }^{1}$, Andreas Schmitz $^{2}$ and Mark-Oliver Rödel ${ }^{1}$
}

\begin{abstract}
Background: Correct species identification is crucial in different fields of biology, and in conservation. The endemic West African frog family Odontobatrachidae currently contains a single described species, Odontobatrachus natator. From western Guinea to western Côte d'Ivoire it inhabits forests around waterfalls or cascades. Based on more than 130 specimens from 78 localities, covering the entire distribution, we investigated the molecular diversity of these frogs.
\end{abstract}

Results: Our analyses included mitochondrial and nuclear genes, with a concatenated alignment of 3527 base pairs. We detected high level of genetic differentiation with five distinct lineages or operational taxonomic units (OTUs). These OTUs were also identified by two different species delimitation approaches, Generalized Mixed Yule Coalescent (GMYC) and cluster algorithm. All OTUs occur in parapatry in the Upper Guinean forests. One OTU, assigned to the "true" Odontobatrachus natator, covers the largest distribution, ranging from the border region of western Sierra Leone-Guinea to eastern Liberia. Two OTUs are restricted to western Guinea (Fouta Djallon and foothills), while two others occur in eastern Guinea and the border region of Guinea-Liberia-Côte d'Ivoire. The OTU representing $O$. natator consists of two divergent subclades: one restricted to the Freetown Peninsula (Sierra Leone) and the other covering all populations further inland. Environmental niche models indicated that the restricted Freetown Peninsula population is separated by unsuitable habitat from remaining populations.

Conclusion: Geographic isolation of OTUs and molecular differences comparable to species level differentiation in other frog families indicate that $O$. natator contains cryptic species diversity. Respective distribution patterns most probably resulted from repeated changes of forest cover (contraction and expansion) over evolutionary timescales. The survival within forest refugia that have persisted through multiple drier periods and subsequent dispersal during wetter times may best explain the observed geographic distributions of OTUs. According to the IUCN Red List range criteria each OTU should be classified as "Endangered." If the Freetown Peninsula "natator" population is recognized as a distinct species it would warrant recognition as "Critically Endangered." The identification of cryptic lineages highlights the urgent need to protect these frogs, all of which are endemic to small areas within the Upper Guinean biodiversity hotspot.

\footnotetext{
* Correspondence: michael@barej.de

${ }^{1}$ Museum für Naturkunde Berlin, Leibniz Institute for Evolution and Biodiversity Science, Invalidenstrasse 43, D-10115 Berlin, Germany Full list of author information is available at the end of the article
} 


\section{Background}

During field work, biologists usually use morphological characters for species identification as a first approach, especially as vision is our prevailing mode of sensory perception. Investigating animals like birds, insects or anurans, experts often additionally rely on acoustics [1-3], but such expertise is sometimes lacking and species identification can remain uncertain. However, correct species identification is of high importance for both basic and applied research in the field including agricultural science of pest species [4], medical treatment [5], ecological studies [6], and conservation efforts [7-9]. A particular problem for correct species delimitation and identification are so-called cryptic taxa [10], herein referring to superficially (morphologically) indistinguishable lineages. Understudied cryptic species complexes may lead to inaccurate scientific results in studies of community ecology $[11,12]$, population assessments in economically exploited species [13], or conservation decisions aimed at retaining phylogenetic diversity [14].

Improved methodologies, such as molecular and acoustic techniques, make biologists increasingly aware of cryptic species and related problems (e.g. the lack of reliable morphological features for identification $[10,15,16])$. Cryptic taxa are not restricted to taxonomic groups or biogeographic regions [17]. These may comprise inconspicuous taxa in pathogenic fungi [18], bryophytes [19], insects [20], small mammals [15,21], birds [1], or reptiles [22], but may also include charismatic organisms such as hammerhead sharks [23], lemurs [24], giraffes [25], and elephants [26].

Quite often complexes of cryptic species include lineages with wide distributions. Molecular analyses provide a reliable and quick approach to search for geographically circumscribed lineages and may facilitate discerning minor but diagnostic morphological differences between these lineages $[8,19,23,27,28]$.

Anuran amphibians have been recognised as a group with various examples of cryptic species [29,30]. Many frog species are superficially similar in morphology and possible minor differences can be difficult to observe in the field [31,32].

Odontobatrachus natator (Boulenger, 1905) is the only species of the frog family Odontobatrachidae, a recently discovered lineage endemic to Upper Guinea, West Africa [33]. These frogs depend on streams with strong currents and cascades or rapids in forested areas. They occur at mid elevations and have a wide but patchy distribution, ranging from western Guinea to western Côte d'Ivoire [34-39]. Upper Guinean montane forests are already known to contain cryptic species in various taxonomic groups including bats [40-42] or rodents [43]. Populations of $O$. natator are known to vary in colouration and shape of glandular dorsal ridges [37,44], and Barej et al. [33,45] recovered unexpectedly high genetic variance between populations. Following these preliminary molecular findings, we conducted a genetic analysis based on more than 130 samples of Odontobatrachus natator covering its entire known range to access molecular variation within this family. We also modelled the potential geographic limits of recognised genetic lineages to delimit their potential distributions. Additionally, we calculated the IUCN Red List criteria "Extent of Occurrence" and "Area of Occupancy" to categorize the potential threat status for each lineage as a basis for conservation decisions.

\section{Results}

\section{Phylogenetic relationships and diversity}

Results of two different phylogenetic methods, Maximum Likelihood (ML) and Bayesian Inference (BI), both were congruent in recovering the same five major OTUs. The tree topology resulting from $3527 \mathrm{bp}$ concatenated mitochondrial and nuclear genes, with respective node support values, is shown in Figure 1a (the expanded tree and a map showing distribution of OTUs in Upper Guinea is provided in Additional file 1). Relationships among these OTUs were not all strongly supported in the ML analysis. The five OTUs formed two divergent major clades, one consisting of three clades from the central and eastern parts of the distribution range, while the second major clade is distributed exclusively in western localities (Figure 2a). A congruent topology has been uncovered in the species tree approach (Figure 1b).

The number of candidate species identified by SpeciesIdentifier (approach 1, see below) depended on the applied threshold values. The number of recognised clusters increased with decreasing threshold values (Additional file 2). Threshold values differed between analysed mitochondrial genes suggesting different evolutionary rates, with $12 S$ being the slowest and $c y t b$ the fastest one. A total of five clusters, corresponding to clades (herein OTUs) in the phylogenetic analyses, as well as the subdivision within natator, are recognized.

Mean uncorrected p-distances of the $16 \mathrm{~S}$ rRNA between the five OTUs, ranged between 3.36-5.21\% (Figure 1c). Summary of $16 \mathrm{~S}$ rRNA uncorrected p-distances within and between OTUs are provided in Tables 1 and 2. Remarkably, natator possessed a sub-division of haplotypes dividing the coastal population from the Freetown Peninsula in Sierra Leone (FP) and the remaining population further inland (IL). This pattern was reflected in intraspecific p-distances within OTUs ranging from $0.36-0.58 \%$ for OTU1-4 and $1.98 \%$ in natator (Figure 1c). Intraclade values within each subclade of natator were $0 \%$ for FP and $0.72 \%$ for the more widespread IL, respectively. A subdivision of natator in two subclades FP and IL corresponded to the increase of recognized clusters in SpeciesIdentifier. The GMYC model (approach 2, see below) identified a robust number of possible OTUs both in the outgroup and 

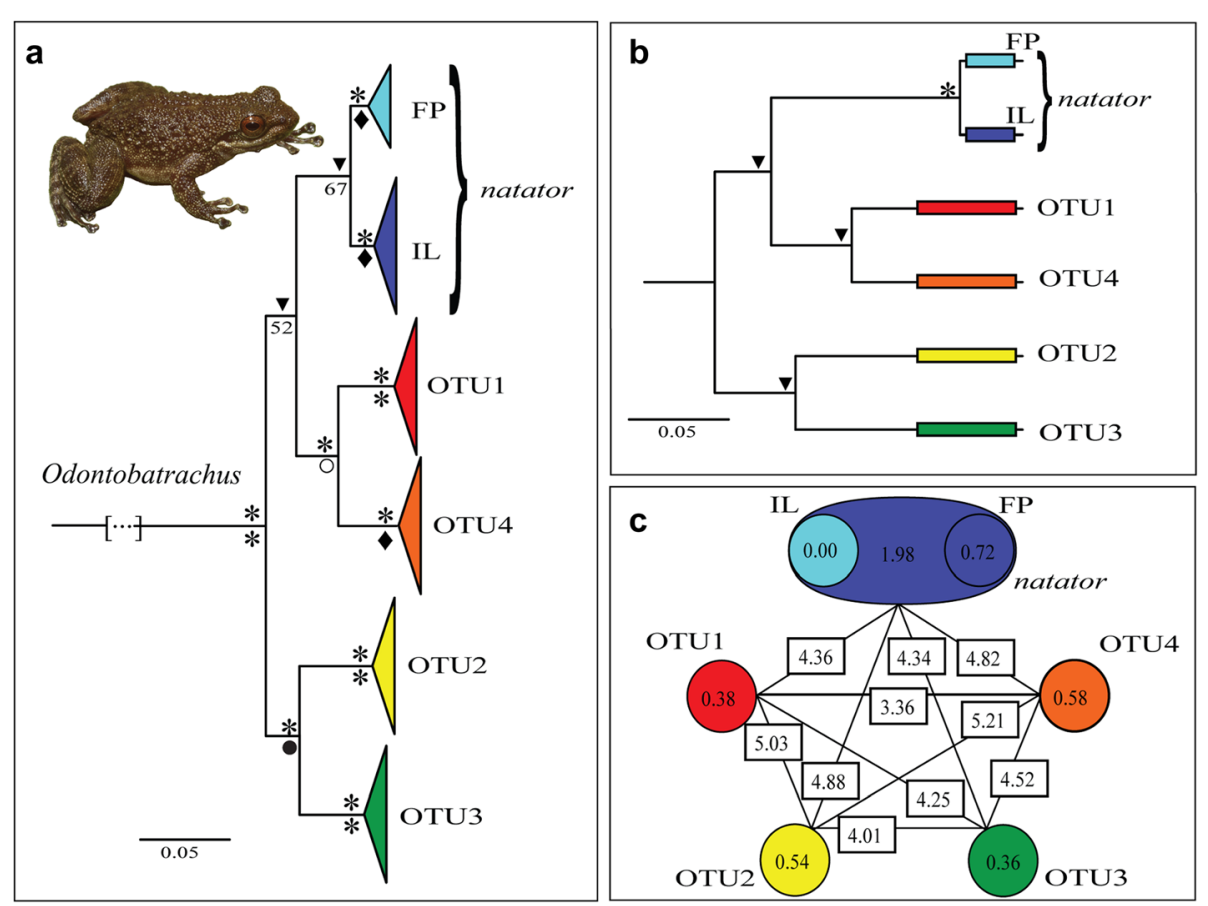

Figure 1 Trees and uncorrected p-distances of Odontobatrachus. (a) Tree resulting from partitioned Bayes and ML analyses of mitochondrial genes 16S, 12S, cytb and nuclear genes RAG1, SIA and BDNF (outgroups not shown). (b) Species tree from mitochondrial DNA data from the Bayesian Inference of Species Trees (STARBEAST). Support values for (a) and (b) are provided as Bayesian posterior probabilities (above branch; PP: ${ }^{*}=1.00 ; 0.95 \geq \boldsymbol{\nabla} \geq 0.99$ ) and Boostrap support values (below branch; BS: ${ }^{*}=100 \% ; 90 \geq \bullet 99 ; 80 \geq \bullet \geq 89 ; 70 \geq 0 \geq 79$ ). (c) Mean uncorrected 165 p-distances between the five OTUs (rectangles) and maximum p-distances within each OTU (circles). Subclades in natator refer to the Freetown Peninsula, Sierra Leone (FP, light blue) and remaining natator population further inland (IL, dark blue). Remark: within p-distances in natator-subclades possess distinctly lower values than the whole OTU natator. Minimum, maximum, mean values and standard deviation of p-distances between and within OTUs are provided in tables 1 and 2.

in the ingroup (Odontobatrachidae, Odontobatrachus). Depending on the priors used to construct the ultrametric tree in BEAST we found a range from 9-14 OTUs in the complete dataset including the four included outgroups (Additional file 3). There was no significant difference between the single- and multiple-threshold approaches; both methods identified either 6 or 7 clusters and between 2-7 singletons. The Yule model with the lognormal relaxed clock produced the lowest number of total groups both with the single- (9) and multiple-threshold (12) approaches, but this approach also produced the largest confidence limit interval in the single-threshold approach (3-13), while all other single approaches produced the same very small confidence interval for the total recovered groups (10-11). Concentrating on the taxa within Odontobatrachus we found that exactly the same OTUs postulated by the other applied methods were identified in the single-threshold approaches, while the multiple-threshold approaches predicted further splits within those previously identified OTUs leading to few singletons (Additional file 4). Dating results based on substitution rates point to very young speciation in Plio-Pleistocene times for the genus
Odontobatrachus (Additional file 5). However, exact timing of splits should be regarded with caution until more recent calibration points are available, enabling a more accurate dating approximation. The original information for the type locality of Odontobatrachus natator (Boulenger, 1905) stated just "Sierra Leone". However, as only one OTU occurred in all known samples from Sierra Leone the assignment of the name natator (colour code: blue) to this particular OTU was without doubt. Although ENMs indicated potential distribution of additional OTUs in Sierra Leone, their presence is unlikely (see below). Sampled localities of OTU natator showed the widest distribution in the genus ranging from western Guinea through Sierra Leone to eastern Guinea and eastern Liberia (Figure 2b). OTU1 (colour code: red) referred to sites in the Simandou Range and the Massif du Ziama in south-eastern Guinea (Figure 2c). OTU2 (colour code: yellow) and OTU3 (colour code: green) covered haplotypes entirely located in western Guinea (Figures 2d, e). OTU4 (colour code: orange) was based on haplotypes from the Nimba Mountains and a few adjacent elevations in south-eastern Guinea and northeastern Liberia, as well as populations from Mont 


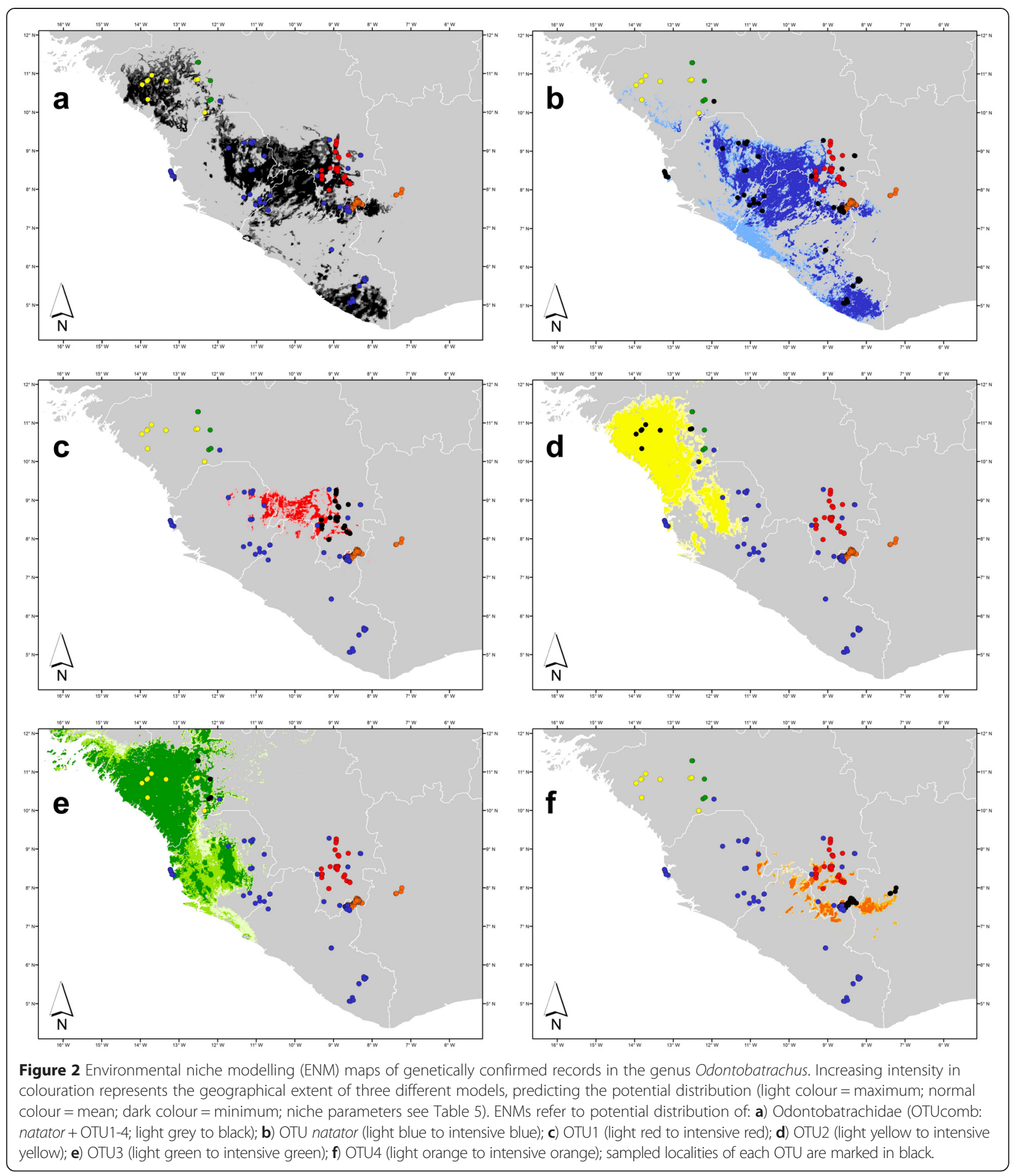

Sangbé National Park in western Côte d'Ivoire (Figure 2f). Phylogenetically, the OTUs from west (OTU2, OTU3) and east (OTU1, OTU4) were closely related, while natator was placed closer to eastern OTUs (Figure 1a). However, the natator placement was not strongly supported in this or other concatenated analyses.

\section{Haplotype networks}

Differences in haploid genotypes of OTUs and their relationships were assessed with unrooted haplotype networks, showing one-step mutations; identical sequences were pooled into a single terminal. Numbers of analysed sequences and uncovered haplotypes were as follows 
Table 1 Uncorrected p-distances between Odontobatrachidae OTUs based on 567 bp of the 16S rRNA gene

\begin{tabular}{llllll}
\hline & natator & OTU1 & OTU2 & OTU3 & OTU4 \\
\hline natator & - & $4.36 \pm 0.21(1216)$ & $4.88 \pm 0.19(1216)$ & $4.34 \pm 0.20(418)$ & $4.82 \pm 0.27(1596)$ \\
OTU1 & $3.74-4.87$ & - & $5.03 \pm 0.14(320)$ & $4.25 \pm 0.13(352)$ & $3.36 \pm 0.22(1344)$ \\
OTU2 & $4.50-5.40$ & $4.86-5.41$ & - & $4.01 \pm 0.11(110)$ & $5.21 \pm 0.17(420)$ \\
OTU3 & $3.97-4.88$ & $3.99-4.53$ & $3.79-4.15$ & - & $4.52 \pm 0.16(462)$ \\
OTU4 & $3.40-5.40$ & $2.89-3.97$ & $4.60-5.55$ & $4.17-4.98$ & - \\
\hline
\end{tabular}

Given are minimum to maximum p-distance values (lower left triangle) for all five major OTUs, natator and OTU1-4 and mean values with standard deviation and in brackets the number of comparisons (upper right triangle).

$\left(\mathrm{N}_{\text {samples }} / \mathrm{N}_{\text {haplotypes }}\right)$ : mitochondrial genes $16 S(133 / 30)$, $12 S$ (123/22), cytb (39/28), nuclear genes RAG1 (38/12), SIA (47/6) and BDNF (39/4). Haplotype networks of mitochondrial genes $(12 S, 16 S, c y t b)$ showed a clear separation of clades and partitioning of haplotypes to a degree of forming distinct and un-associated subnetworks for all five OTUs (Figure 3a-c). Comparable to the results above, natator formed two distinct subclades. These were un-associated in $c y t b$ (Figures 3c), divided by a minimum of nine mutation steps in the $16 \mathrm{~S}$ gene (Figure 3a) and even in the slowest mitochondrial gene, 12S, FP samples were separated from remaining natator-haplotypes (Figure $3 \mathrm{~b}$ ). Concerning nuclear markers, solely the RAG1 gene exhibited a differentiation and privatization of the five OTUs, even separating FP haplotypes in natator from remaining localities (Figure $3 \mathrm{~d}$ ). In contrast, BDNF and SIA showed little variation and a large overlap of shared haplotypes of the five OTUs and within natator (Figure 3e, f).

\section{Diagnostic nuclear sites}

Four sites in the RAG1 gene and a single site in SIA supported two major groupings and distinguished the western OTU2 and OTU3 from more eastern natator, OTU1 and OTU4. Additionally, the five OTUs were defined in nuclear genes by a few deviating sites only.

Table 2 Uncorrected intra-OTU p-distances in Odontobatrachidae OTUs based on 567 bp of the $16 \mathrm{~S}$ rRNA gene

\begin{tabular}{llllll}
\hline & min & max & mean & SD & N \\
\hline OTU1 & 0.00 & 0.38 & 0.18 & 0.15 & 496 \\
OTU2 & 0.00 & 0.54 & 0.20 & 0.19 & 45 \\
OTU3 & 0.00 & 0.36 & 0.15 & 0.15 & 55 \\
OTU4 & 0.00 & 0.58 & 0.05 & 0.11 & 861 \\
natator (FP + IL) & 0.00 & 1.98 & 0.42 & 0.51 & 703 \\
natator (IL) & 0.00 & 0.72 & 0.27 & 0.21 & 630 \\
natator (FP) & 0.00 & 0.00 & 0.00 & - & 1
\end{tabular}

Given are minimum (min), maximum (max), standard deviation (SD) and sample size ( $\mathrm{N}=$ number of pairwise comparisons) for all five major OTUs, natator and OTU1-4, as well as the subdivision within O. natator following molecular and distributional subdivision (FP, IL).

\section{Environmental niche modelling}

Overall the ENMs performed well, with training AUC values of 0.9915-0.9985 and test AUC values of 0.99060.9982 in individual OTUs and OTUcomb (Additional file 6). Only in OTUcomb and natator all parameters contributed to ENMs (Additional file 7). Highest contributions in OTUs were as following: in OTUcomb highest precipitation value or wettest month (prec30_max 43.96\%) and total annual precipitation (prec30_sum 28.95\%) had highest predictive power; in OTU natator highest precipitation value (wettest month; prec30_max $34.83 \%$ ) and total annual precipitation (prec30_sum $34.64 \%$ ); in OTU1 total annual precipitation (prec30_sum 30.07\%) and lowest precipitation value (driest month; prec30_min 22.34\%); in OTU2 standard deviation of the precipitation (prec30_std 49.90\%) and percentage of bare ground (MODIS; bare_4x4 25.75\%); in OTU3 standard deviation of precipitation (prec30_std $46.14 \%$ ) and percentage of bare ground (MODIS; bare_4x4 $38.12 \%)$; in OTU4 lowest precipitation value (driest month; prec30_min 31.00\%), elevational variance calculated from the SRTM30 data set using a 9x9 moving window (srtm_v_ln_9x9 25.63\%) and highest precipitation value (wettest month; prec30_max 24.39\%). Consequently, parameters with highest contribution in OTU2 and OTU3 were identical (OTU2/OTU3: percentage of bare ground and standard deviation of precipitation), while OTUs natator, OTU1 and OTU4 had one parameter in common respectively (OTU1/OTU4: driest month; OTU1/natator: total annual precipitation; OTU4/natator: wettest month).

ENMs of potential distribution of the family Odontobatrachidae (OTUcomb) revealed an area smaller than just superposed ENMs of all separate OTUs (Figure 2a). However, it showed that samples included herein covered the entire distribution of this family. Considering ENMs the border area between Sierra Leone-GuineaLiberia might inhabit up to three OTUs of odontobatrachid frogs, however records from that area lack so far. ENMs of natator predominantly covered the border area of these three countries (westwards through Sierra Leone into western Guinea), and south-eastern Liberia with some extensions into western Côte d'Ivoire (Figure 2b). Moreover, a distinct gap of apparently unsuitable area 

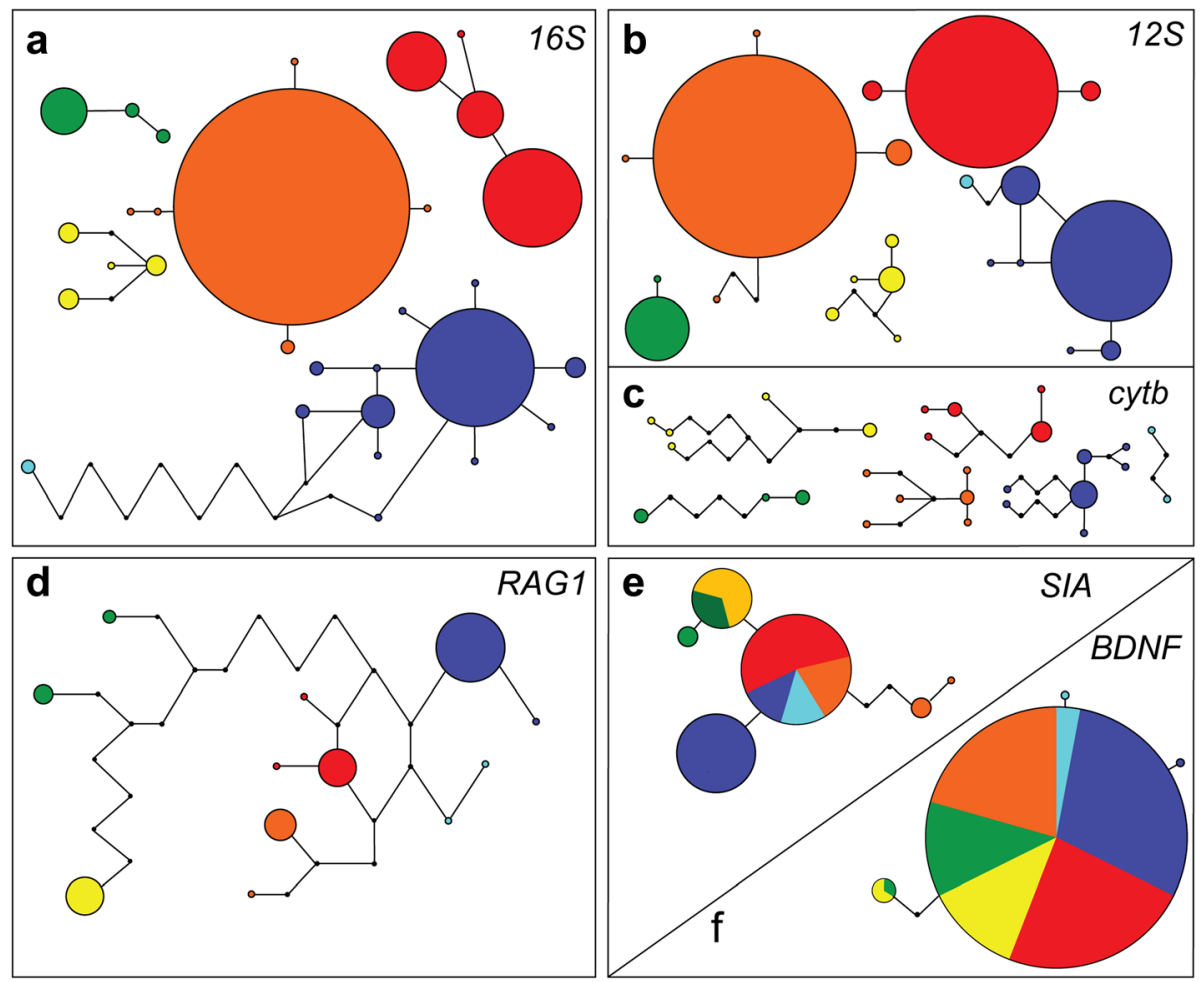

Figure 3 Parsimony networks of haplotypes in Odontobatrachidae. Networks corresponding to mitochondrial genes $165(\mathbf{a} ; \mathrm{N}=133), 12 S$ (b; $N=123)$, cytb (c; $N=39)$ and nuclear genes RAG1 ( $\mathbf{d} ; N=38)$ and $S I A(\mathbf{e} ; N=47)$ and BDNF (f; $N=39)$ sequence variation from analysed samples. The colours correspond to distribution maps (Figure 2) and trees (Figure 1): natator (IL; dark blue), natator (FP; pale blue), OTU1 (red), OTU2 (yellow), OTU3 (green) and OTU4 (orange). Mitochondrial genes (a-c) show un-associated sub-networks and two nuclear genes (e, $\mathbf{f}$ ) show almost identical haplotypes. The size of the circles is proportional to the number of alleles for each gene.

separated natator localities around Freetown, Sierra Leone from other populations further inland Figure $2 b$ ). ENMs of OTU1 covered parts of south-eastern Guinea and westwards into Sierra Leone (Figure 2c). ENMs of OTU2 and OTU3 showed a largely overlapping potential area of distribution in western Guinea and Sierra Leone (Figure 2d, e). ENMs of OTU4 covered areas in south-eastern Guinea/northern Liberia and further westwards reaching eastern Sierra Leone (Figure 2f). Generally, ENMs of OTU1 and OTU4 showed very little or no overlap in their potential distribution with OTU2 and OTU3. Concerning sampled localities, only natator possessed areas overlapping distribution ranges of eastern OTUs (OTU1 and OTU4) in south-eastern Guinea and reaching easternmost distribution boundaries of western OTUs (OTU2 and OTU3) in western Guinea, respectively (Figure 2).

\section{Conservation status}

Both applied species delimitation methods revealed 5-6 OTUs within Odontobatrachus. We examined their potential conservation status, at first in a more conservative approach (5 OTUs). In a second step we assess the potential conservation status of two lineages within "natator". Following the IUCN Red List geographic range criterion the calculated EOOs classified OTU1 and OTU2 as "Vulnerable." OTU3 and OTU4 as "Endangered" and only natator as of "Least Concern" (Table 3). In contrast, AOO calculations depicted ranges classifying all five OTUs as "Endangered." If both natator subclades are recognised as distinct species, the Red

Table 3 Summary of IUCN Red List criteria for Odontobatrachidae OTUs

\begin{tabular}{|c|c|c|c|c|}
\hline & \multicolumn{2}{|r|}{ AOO } & \multicolumn{2}{|r|}{ AOO } \\
\hline & $\mathrm{km}^{2}$ & RL category & $\mathrm{km}^{2}$ & RL category \\
\hline OTU1 & 7.797 & Vulnerable & 104 & Endangered \\
\hline OTU2 & 12.673 & Vulnerable & 40 & Endangered \\
\hline OTU3 & 1.318 & Endangered & 20 & Endangered \\
\hline OTU4 & 2.529 & Endangered & 156 & Endangered \\
\hline natator & 180.231 & Least Concern & 224 & Endangered \\
\hline natator (IL) & 132.175 & Least Concern & 204 & Endangered \\
\hline natator (FP) & 34 & Critically Endangered & 20 & Endangered \\
\hline
\end{tabular}

IUCN Red List (RL) range criteria for all OTUs and the two natator subclades, resulting from calculation of the Extent of Occurrence (EOO) and Area of Occupancy (AOO) [126]. Decisive category marked in bold letters. Additionally, results are provided for both natator subclades (Freetown Peninsula =FP; inland = IL) independently in case they represent distinct species. 
List category for the Freetown Peninsula subclade would change to "Critically Endangered" due to its low AOO (Table 3).

\section{Discussion}

Taxonomic decisions in cryptic species complexes are usually based on subtle morphological characters. Morphological congruence not only impedes species recognition, due to absence of striking differences, but the whole description process itself as statistically exploitable numbers of vouchers are needed to recognize differences in otherwise overlapping morphometrics. Because genetic divergence accompanied by morphological similarity is not uncommon, cryptic speciation either remains overlooked $[28,46]$ or species diagnoses focus exclusively on molecular markers [47].

Our analyses of the West African torrent-frog Odontobatrachus natator, presumed to be widely distributed, uncovered a cryptic diversity within this unique evolutionary lineage [33]. Based on analyses of concatenated mitochondrial and nuclear loci, we recognize five OTUs in the family Odontobatrachidae. Both applied species delimitation approaches indicate the presence of five or six candidate species within Odontobatrachus, corresponding to OTUs in the phylogenetic analyses, respectively. The mitochondrial $16 S$ gene is commonly used for barcoding approaches in anuran amphibians $[29,30,48]$, and uncorrected p-distances recognized between OTUs are comparable to species level differences in nonrelated frog genera and families thus pointing to cryptic speciation in Odontobatrachus (min-max: 2.89-5.55\%; Table 1; compare [2,30,49-54]). Recognized p-distances within each OTU were considerably lower than $0.72 \%$ (Table 2).

Mitochondrial genes demonstrated utility for determining lineages of geographically separated OTUs $[49,55]$ and all five OTUs have discrete $16 S, 12 S$ and cytb haplotypes. Of the nuclear genes, solely RAG1 distinguished all five OTUs by discrete haplotypes. Geographically adjacent OTUs have been pooled in two of three nuclear genes (RAG1: $4 \mathrm{bp}$; SIA: $1 \mathrm{bp)} \mathrm{supporting} \mathrm{a} \mathrm{geographical} \mathrm{split} \mathrm{of}$ the western (OTU2, OTU3) against the remaining OTUs in the Upper Guinean forests (Figure 3). Differences in the level of separation in nuclear genes may be due to incomplete lineage sorting at each single nuclear loci or different evolutionary rates $[56,57]$.

The unexpected recognition of five distinct OTUs raised the necessity to assign the officially described taxon Odontobatrachus natator (Boulenger, 1905) to one of them. Despite the fact that ENMs indicated the potential occurrence of all OTUs in Sierra Leone, all sampled localities from Sierra Leone belonged genetically to a single OTU. The type locality of $O$. natator is Sierra Leone, consequently the respective OTU was assigned to the nominate taxon (Figure 2). Generally, OTUs showed a parapatric distribution in Upper Guinea and distribution patterns in the family Odontobatrachidae are now regarded as follows (Figure 2a): O. natator has the widest range and is present in lowlands to mid-altitudes from the southern edge of the Fouta Djallon in western Guinea to eastern Liberia and southeastern Guinea (200-1350 m a.s.l.); OTU1 occurs in lowlands to mid-elevations north of the Nimba Mountains in south-eastern Guinea (e.g. Simandou Range, Massif du Ziama, Mont Bero; app. 450-1300 m a.s.l.); OTU2 occurs in lowlands in western Guinea (the Fouta Djallon massif and its western extensions into the Télimélé region; app. 100-650 m a.s.l.); OTU3 likewise occurs in western Guinea but at higher elevations (Fouta Djallon; app. 650-900 m a.s.l.); OTU4 occurs in lowlands to mid elevations in the border area Guinea-Liberia-Côte d'Ivoire and further east (Mount Sangbé in western Côte d'Ivoire, the Nimba Mountains and adjacent Mount Gangra; app. 400-1300 m a.s.l.). Consequently, geographic separation and genetic distinctness of OTUs at the species-level, identify Odontobatrachus natator as a complex of cryptic species.

Potential geographic ranges based on ENMs exceeded the known distribution ranges in four of five OTUs; the only exception is natator (Figure 2). OTU1 and OTU4 could be widely distributed in eastern Guinea and the border region of Sierra Leone-Guinea-Liberia, while OTU2 and OTU3 could occur in central Sierra Leone and even enter Guinea-Bissau in the case of OTU3 (Figure 2). However, we believe that these predictions are unlikely. Given our own dense sampling of the entire Upper Guinea forest zone, it is reasonable to assume that the observed ranges are close to the known ranges of all five OTUs. Field observations coarsely explain the occurrence of Odontobatrachus by two factors: 1) forest cover and 2) slopes (in different elevations) with fast-flowing streams of various sizes, including waterfalls and cascades. As various areas in the Upper Guinean forests are apparently suitable to several OTUs and geographic barriers, such as large rivers or mountain chains do not exist in this area ([58] the one exception, the Kolenté river, bordering Guinea and Sierra Leone, might separate natator and OTU2), competitive exclusion due to niche occupation by natator may shape the distributions of OTU1-4 [59].

OTUs more closely related to each other are likewise spatially closer: a western clade is present in the Fouta Djallon highlands and its western extensions (OTU2, OTU3), and the central-eastern clade occurs in the Guinea Highlands, running from southern Fouta Djallon through northern Sierra Leone and Liberia to western Côte d'Ivoire (natator, OTU1, OTU4; Figure 2a). A potential scenario responsible for such a distribution might be the fluctuations in African palaeo-environments and repeated expansion and contraction of suitable forested 
habitat for species such as those of the family Odontobatrachidae [60-62]. The refuge theory aims at explaining how such forest refugia, especially montane forests, have boosted speciation in forest dependent species during past arid epochs [63-65]. The role of Upper Guinean forests as refugia is uncontroversial $[65,66]$. But, knowledge concerning the exact historical process (timing and geography) of West African refugia remains scarce [67]. In particular the existence and geographic position of socalled micro-refugia, small forest areas outside postulated larger refugia, is unclear. However, these may be particularly important for the persistence of a large portion of regional biodiversity [68].

Close relationships between Odontobatrachus OTUs cause a lack of resolution in slow-evolving nuclear genes (Figure 3e, f). Despite a clear resolution, likewise the comparatively low number of changes in fast evolving mitochondrial genes $12 S$ and $16 S$ points to rather recent splits, and the following speciation scenario seems most likely. While calculations of node ages should be regarded with caution until more recent calibration points are available, calculated node ages younger than $3 \mathrm{Ma}$ support very young (Plio-Pleistocene-)speciation events in the genus Odontobatrachus (Additional file 5). Torrent frogs may have evolved in the Central Guinea Highlands (max. app. $1950 \mathrm{~m}$ a.s.l.), and then colonised westwards to the Fouta Djallon (max. app. $1500 \mathrm{~m}$ a.s.l.) and eastwards to the Simandou Range-Nimba Mountains (app. $1700 \mathrm{~m}$ a.s.l.), always settling along fast running streams in forests (Additional file 8). For the Plio-Pleistocene several aridity-dominated periods are known [61] and while open habitats dominated the landscape in Upper Guinea, torrent frogs have probably only prevailed in isolated montane forests as it is also assumed for other forestdependant groups [67]. The Fouta Djallon as well as the Simandou Range-Nimba Mountains are known to comprise many endemic species [69-72] and both are assumed to play a role as Upper Guinean forest refugia $[66,71,73]$. A subsequent turn of forest expansion and contraction might have resulted in sister relationship of OTUs in eastern and western Upper Guinea (east: OTU1/OTU4 and west: OTU2/OTU3; Figures 1a and 2a). The Loma Mountains-Tingi Hills area (app. 1900 m a.s.l.) in Sierra Leone might have served as the refuge for natator in central Guinea Highlands (Additional file 8). The latest expansions of forests and increase of suitable habitats was apparently exploited best by natator as this OTU shows the widest distribution. Probably a population of natator was likewise pushed back to coastal elevations of the Peninsula Mountains (app. $900 \mathrm{~m}$ a.s.l.) during relatively cold climates, resulting in molecular divergence. Today, both natator subclades are separated by unsuitable habitat due to lack of forest cover that might result from environmental changes in more recent times $[74,75]$ and not least from anthropogenic deforestation, e.g. during colonization events [76] and before.

Differing dispersal patterns of Odontobatrachus OTUs, showing differences in size of distribution areas, could result from minor differences in: habitat requirements, ecological adaptations or persistence in more widespread micro-refugia. Such ecological data should be searched for in future studies of this genus. However, ENMs revealed that closer related OTUs (natator/OTU1/OTU4 vs. OTU2/OTU3) share important factors shaping their potential distribution which play a minor role for the sister clade (Additional file 7). Generally, precipitation played an important role in shaping distribution of all OTUs although important precipitation parameters differed between OTUs (OTU1/OTU4: driest month; OTU1/natator: total annual precipitation; OTU4/natator: wettest month; OTU2/OTU3: standard deviation of precipitation; Additional file 7).

In conclusion, the assumed monospecific West African frog family Odontobatrachidae obviously contains several undescribed species. Distribution patterns provide first insights into the subdivisions of the Upper Guinean forest refugium, but knowledge on the ecological requirements leading to the present distribution patterns of these frogs is incomplete and requires further investigation to support our hypotheses.

\section{Conservation concern}

Amphibian declines occur around the world and in all major habitat types, with forest species showing highest losses [27]. West Africa represents a distinct biodiversity hotspot [58,77]. Its major threats are rapid deforestation, often including degradation and fragmentation, and the increase of agricultural encroachment and mining in Upper Guinean Mountains [78-85]. Taxa with narrow habitat niches are highly threatened by habitat loss and fragmentation effects [86], and because of their dependence on fast flowing streams in forested areas this applies to the West African torrent frogs. At present, Odontobatrachus natator has been assigned the IUCN Red List category "Near Threatened" [87], with a trend of decreasing populations. However, our results indicate that the different OTUs represent distinct species, and thus should then be classified as "Endangered." If the two subclades of natator are recognized as distinct species, the Freetown Peninsula population would require the Red List category "Critically Endangered". Today's conservation efforts should concern distinct genetic lineages within species [88-90] and consequently should be applied to $O$. natator s.l. as well.

Although Guinea exhibits the highest diversity of the family Odontobatrachidae, with all five OTUs, the network of protected areas is poor [91]. Considering the distribution of this family, only three OTUs occur in 
protected areas (herein maintained as National Parks and Biosphere Reserves; Additional file 9). However, even in protected areas threats to herein defined OTUs are evident: natator (Sierra Leone: Gola Forest National Park, Western Area Peninsula Forest Reserve - urban growth; Liberia: Sapo National Park - stone mining), OTU1 (Guinea: Massif du Ziama Biosphere Reserve - agricultural encroachment, timber exploitation), OTU4 (Guinea/ Liberia/Côte d'Ivoire: Mount Nimba Strict Nature Reserve mining [92]; Côte d'Ivoire: Mont Sangbé National Park current status unclear after recent political crisis in Côte d'Ivoire). While both natator-subclades occur in protected areas, OTU2 and OTU3 (Guinea: Fouta Djallon - logging of gallery forests, local population and tourist activities [39]) are entirely unprotected at present.

Almost everywhere throughout its distribution range Odontobatrachus natator s.l. occurs sympatrically with Conraua alleni, the latter inhabiting more slowly-running parts of streams. While C. alleni is already listed as "Vulnerable" [87] this classification is probably insufficient as high genetic diversity indicates another cryptic complex ([87]; Barej et al. unpubl. data). Consequently, any conservation effort concerning Odontobatrachus could also maintain lineages of the $C$. alleni complex, as well as other forest and stream dependent taxa of other taxonomic groups, not yet in focus of any more in detail research activities.

\section{Conclusions}

A large-scale molecular assessment of the West African endemic family Odontobatrachidae throughout its distribution range revealed the presence of distinct Operational Taxonomic Units (OTUs). Bayesian methods and ML uncovered five OTUs, which show a parapatric distribution and slight differences in parameters contributing to respective environmental niche models. OTUs most likely represent distinct species and challenge the monospecific status of Odontobatrachidae. The assigned nominate form Odontobatrachus natator revealed two subclades in both analyses, which are geographically separated by unsuitable habitat. Following IUCN Red List criteria all five OTUs should be classified as 'Endangered' if later recognized as distinct species. Only two OTUs currently occur in protected areas, while all are endangered through habitat loss. Knowledge of forest refugia within the Upper Guinean forests is scarce but the distribution pattern of Odontobatrachidae OTUs suggest likely refugia within the Fouta Djallon, Simandou Range-Nimba Mountains, Loma Mountains-Tingi Hills and the Peninsula Mountains.

\section{Methods}

DNA extraction, amplification and sequencing

A total of 135 samples from 78 localities covering the entire distribution of the family Odontobatrachidae, ranging from Guinea, Sierra Leone, Liberia and Côte d'Ivoire were analysed (map of most important elevations see Additional file 10). Collected frogs were anesthetized with either chlorobuthanol or benzocaine and fixed in $4 \%$ formalin or $75 \%$ ethanol. Voucher specimens were finally stored in $75 \%$ ethanol. Tissues were taken either from fresh specimens collected in the field or preserved museum specimens, either by toe clips, liver or muscle tissue. DNA extraction, amplification, and sequencing follow the methodology of Barej et al. [45]. For quality assurance we sequenced both directions of the amplified PCR product (using an external vendor, Macrogen). Available samples were barcoded for two standard mtDNA markers (12S and $16 S$ ) for a preliminary assignment to major clades, and representatives of preliminary distinct populations were subsequently sequenced for three nuclear (Seven-in-Absentia [SIA], Recombination Activation gene 1 [RAG1] and Brain-derived neurotrophic factor $[B D N F])$ and one additional mitochondrial coding gene (cytochrome $\mathrm{b}$ gene $[c y t b]$ ). Respective primers are given in Barej et al. [45]. A full list of samples, their museum collection number and locality data as well as respective GenBank [93] numbers (KP005071-KP005450) are given in Additional file 11.

\section{Phylogenetic analysis}

Sequences were checked for reliability using the original chromatograph data in the program BioEdit [94], aligned using ClustalX [95] and the alignment checked by eye. Protein coding partitions of mitochondrial and nuclear genes (cytb, BDNF, SIA, RAG1) were translated to amino acids with the program TranslatorX [96] to set codon positions and confirm absence of stop codons. The final alignment of all six genes, including nuclear and mitochondrial loci, consisted of 3527 base pairs. Sequence lengths were as following: $383 \mathrm{bp}$ of $12 S, 567 \mathrm{bp}$ of $16 \mathrm{~S}$, $576 \mathrm{bp}$ of $c y t b, 675 \mathrm{bp}$ of BDNF, $396 \mathrm{bp}$ of SIA, $930 \mathrm{bp}$ of RAG1.

Two techniques for phylogenetic estimation were applied: Bayesian Inference (BI; MrBayes, 3.21 x64; [97,98]) and Maximum Likelihood (ML; RAxML 7.0.4; [99] using the rapid hill climbing algorithm following Stamatakis et al. [100]). While ML analyses were run under the GTR + $G$ model in RAxML, BI used recognized partition schemes identified with PartitionFinder 1.1.1 [101], models of substitution are provided in Table 4. Additionally we analysed an unpartitioned dataset and a maximally partitioned dataset (Additional file 12). For this purpose, the Bayesian information criterion (BIC) for each gene partition (and respectively codon positions P1, P2, P3) was selected using jModelTest 2.1.4 [102]; models of substitution are provided in Table 4. The next more complicated model (in regard to number of substitutions, amongsite variation, number of rate categories for the gamma 
Table 4 Partition schemes and models of substitution

\begin{tabular}{|c|c|c|c|c|c|}
\hline \multicolumn{3}{|c|}{8 partitions } & \multicolumn{3}{|c|}{14 partitions } \\
\hline & substitution model & included partitions & & substitution model & included partitions \\
\hline 1 & $\mathrm{GTR}+\mathrm{G}$ & 12S, 16S; cytb (P1) & 1 & $\mathrm{TIM} 2+\mathrm{G}$ & 125 \\
\hline 2 & $F 81+1$ & $B D N F(\mathrm{P} 1), \operatorname{Rag} 1(\mathrm{P} 1)$ & 2 & $\mathrm{TIM} 2+1+\mathrm{G}$ & 165 \\
\hline 3 & $J C$ & $B D N F(P 2), S I A(P 2)$ & 3 & $\mathrm{TIM} 2+\mathrm{I}+\mathrm{G}$ & cytb (P1) \\
\hline 4 & $\mathrm{~K} 80+\mathrm{G}$ & $B D N F(\mathrm{P} 3)$ & 4 & TPM2uf + G & cytb (P2) \\
\hline 5 & $K 80+1$ & RAG1 (P2), SIA (P1) & 5 & $\mathrm{TIM} 1+1+\mathrm{G}$ & cytb (P3) \\
\hline 6 & $\mathrm{~K} 80+\mathrm{G}$ & RAG1 (P3), SIA (P3) & 6 & $\mathrm{GTR}+\mathrm{I}$ & RAG1 (P1) \\
\hline 7 & $H K Y+G$ & cytb (P2) & 7 & $\mathrm{TIM} 1+\mathrm{I}$ & RAG1 (P2) \\
\hline \multirow[t]{2}{*}{8} & $\operatorname{TrN}+1$ & cytb (P3) & 8 & $H K Y+I$ & RAG1 (P3) \\
\hline & & & 9 & TrNef & $S I A(P 1)$ \\
\hline \multicolumn{2}{|c|}{4 partitions } & & 10 & $J C$ & $S I A(P 2)$ \\
\hline 1 & $\mathrm{GTR}+\mathrm{G}$ & 12S, 16S, cytb (P1) & 11 & TPM2uf + G & $S I A(P 3)$ \\
\hline 2 & $J C+1$ & RAG1 (P1), RAG1 (P2) & 12 & $\mathrm{~K} 80+\mathrm{G}$ & $B D N F(\mathrm{P} 1)$ \\
\hline 3 & $H K Y+G$ & cytb (P2), RAG1 (P3) & 13 & $J C$ & $B D N F(P 2)$ \\
\hline 4 & $\operatorname{TrN}+1$ & cytb (P3) & 14 & $J C$ & $B D N F(\mathrm{P} 3)$ \\
\hline
\end{tabular}

Models of substitution applied in the Bayesian inference (8 partitions; PartitionFinder) and the maximally partitioned dataset (14 partitions; jModelTest). Models of substitution applied in the dating analysis (4 partitions, PartitionFinder).

distribution, considering the mitochondrial or universal code) was implemented when jModelTest results were not applicable. Results of single gene analyses are provided in Additional file 13. Included outgroups (not shown) were Hyperolius ocellatus, Conraua alleni, C. goliath and Petropedetes juliawurstnerae (GenBank numbers provided in Additional file 11).

Support values for the two phylogenetic approaches were calculated. Bootstrap analyses (BS) with 1000 pseudoreplicates evaluated the relative branch support in the ML analysis. Bayesian analyses were run under partitioned schemes for 5 million generations with four chains sampled every 100 generations, with a burn-in of 1000 trees. Clades with posterior probabilities $(\mathrm{PP}) \geq$ $95 \%$ were considered strongly supported. Stationarity of Bayes results was checked with Tracer 1.6 [103]. Uncovered strongly supported molecular lineages were defined as operational taxonomic units (OTU) to render distributional delimitation and molecular comparisons possible. Uncorrected p-distances between OTUs and within OTUs were calculated with PAUP* 4.0b10 [104] for the partial $16 \mathrm{~S}$ rRNA gene as these values were often used to prove distinctness at the species level $[29,30]$.

\section{Haplotype networks}

Haplotype networks of genealogical relationships for single mitochondrial and nuclear genes were constructed with the software TCS 1.21 [105] with a connection limit of 95\% as implemented in the software. Haplotype frequencies were considered and haplotypes coloured according to recognised OTUs. Shared haplotypes are provided as pie charts and colours reflect the proportionate factor of respective integrated main lineages.

\section{Species tree}

A species tree was generated with the software package BEAUti and BEAST 1.7.5 and the implemented approach "BEAST $[106,107]$. The analysed data set included all samples covering all mitochondrial genes. This approach required a priori definition of 'species' (referring to herein phylogenetically identified OTUs) which have been entered according to the phylogenetic results. Resulting log files were checked via Tracer 1.5.0 and trees combined with the software LogCombiner 1.7.5 and TreeAnnotator 1.7.5 with $10 \%$ of the trees discarded as burn-in. The final trees were visualised with FigTree 1.4.0 [108].

\section{Species delimitation}

The genetic diversity within Odontobatrachus natator was examined on the basis of the mitochondrial genes $16 S, 12 S$ and cytb (approach 1 see below) or the concatenated alignment including all mitochondrial and nuclear genes with the exception of the position 2 of the SIA codons, since this position turned out to be nearly invariable for the dataset (approach 2). While approach 1 considers overlaps between intra- and interspecific variation, approach 2 seeks to identify groupings on the species-level versus population level resulting from tree shape and branch lengths of a given tree.

In approach 1, OTUs were assessed using the software TaxonDNA 1.7 and the implemented 'Cluster' algorithm in SpeciesIdentifier [109]. OTUs, therein termed clusters, 
are identified according to pairwise distances for sequences within each cluster. We herein reduced the data set to unique haplotypes for each applied gene. Incremental values ranged from $0.5 \%$ (exceptionally 0.75 in $12 S$ ), with an increase of $0.5 \%$ each step, to a maximum of $4.5 \%$. However, the calculations were stopped if all haplotypes were grouped in a single cluster/OTU. The maximum pairwise distance within recognized OTUs (a putative species-level) should not exceed a given threshold.

In approach 2 we examined the clustering of the ingroup taxa (Odontobatrachidae, Odontobatrachus) by detecting the boundaries between species-level and population-level with the GMYC approach [110-112]. GMYC can use either the Yule model (for lineage diversification processes) or the coalescent model (for populationlevel diversification) and find the respective transition in branching rates between them. We used both the single transition [110] and the multiple transition [112] approaches. Observed branching rates were subjected to a log-likelihood ratio test (LRT) which uses a nullhypothesis suggesting no shift in the branching rate. If shifts are observed in the branching rates, one can assume more than one OTU in the used dataset. For the GMYC analyses we used ultrametric trees that were created with a random starting tree, and the GTR + I + $\mathrm{G}$ model of sequence evolution in BEAST [113]. To assure a stable result not influenced by priors we followed the approach of Gehring et al. [114] and created 4 different ultrametric trees which were generated using 1) a Yule model for the tree prior, with a strict molecular clock (fixed to a rate of 1.0), 2) a Yule model with a lognormal relaxed clock, 3) a coalescent model with a strict clock, and 4) a coalescent model with a lognormal relaxed clock. The GMYC web server (The Exelixis Lab: http://species.hits.org/gmyc/) was used to fit our four trees to both single-transition and multiple-transition GMYC models.

\section{Dating estimates}

Dating was performed with the software package BEAUti and BEAST 1.8.1 [106,107] on a reduced dataset consisting of the complete ingroup (Odontobatrachus OTUs) and a single outgroup (Petropedetes juliawurstnerae). Additionally, we deleted the slow evolving nuclear genes $S I A$ and BDNF from the dataset since they had not accumulated enough mutation in the ingroup to show any resolving power (see haplotype networks Figure 3e, f); this lead to a full dataset of $2446 \mathrm{bp}$ of coding and noncoding genes (Additional file 5). Partition schemes were again calculated with PartitionFinder 1.1.1 [101], for identified models of substitution see Table 4 .

To accommodate for the comparatively short branch length identified in the full analyses the data were run under a Coalescent speciation model [115] and the lognormal relaxed clock model [116], using a random starting tree. Because of the lack of suitable calibration points for the evolutionary history of the ingroup we modelled informative priors for the mutation rates only, using the published data [117-119] (means of 0.0125 for the combined mitochondrial genes and 0.00262 for the RAG1 gene, respectively), both with a normal distribution and a relaxed standard deviation of 0.1. To check for inconsistencies between the mitochondrial and the nuclear gene mutation rates, we ran analyses using the mitochondrial priors only as well as priors for both the mitochondrial and nuclear genes together. We ran all analyses for 1.25 billion generations total (5 runs of 250 million generations, with a burn-in of 20 million and 25 million generations for the mitochondrial only and combined mitochondrial-rag1 dataset, respectively). Convergence and mixing of the parameters for each run were checked in Tracer 1.6 [103].

\section{Environmental niche modelling (ENM)}

In order to assess the potential current distribution of recognised OTUs in the Upper Guinea forests, ENMs were calculated. ENM as a statistical modelling tool seeks to determine relationships between species occurrences and environmental parameters within data sets. Based on such correlations, potential distributions can be modelled. We applied ENMs using maximum entropy principles (using the software Maxent 3.3.3.k [120-122]) by comparing values of variables at sites where the species was found against data from randomly chosen sites where the species was absent (background). As incorrect absence information might be counterproductive, a conservative approach based on confirmed presence only was chosen. Maxent is one of the best ENM techniques when using presence-only data $[123,124]$. A total of 18 continuous parameters (5 environmental, 10 climatic, 2 altitudinal, 1 distance-based; Table 5) were analysed on a 30 arc second grid (app. $1 \mathrm{~km}^{2}$ ) on a continental scale and clipped back to the Upper Guinea forest area within West Africa. Climatic parameters corresponded to average values from 1950 to 2000 (for details see Table 5). Environmental parameters were based on satellite imagery (SPOT4 \& MODIS). Altitudinal parameters were converted from a radar derived data set (SRTM). Following Penner et al. [125] a total of 100 ENMs were calculated and replicated using sub-sampling (70\% model training and 30\% model testing) and finally three average models were derived: maximum, mean and minimum prediction gained. Average 10 percentile thresholds were applied over all ENMs to gain three binomial models from maximum, mean and minimum models. Validation of models was performed with the area under the curve (AUC) criterion, which corresponds to the receiver operating characterising (ROC) curve; a threshold-independent measurement widely accepted for such models [123]. 
Table 5 Parameters used in the environmental niche modelling (ENM) approach

\begin{tabular}{|c|c|c|c|c|}
\hline & Category & Parameter & Description & Original source \\
\hline 1 & climate & tmin30_max & highest value of the minimum temperatures & {$[127]$} \\
\hline 2 & climate & tmin30_min & lowest value of the minimum temperatures & {$[127]$} \\
\hline 3 & climate & tmin30_std & standard deviation of the minimum temperatures & {$[127]$} \\
\hline 4 & climate & tmax30_max & highest value of the maximum temperatures & {$[127]$} \\
\hline 5 & climate & tmax30_min & lowest value of the maximum temperatures & {$[127]$} \\
\hline 6 & climate & tmax30_std & standard deviation the maximum temperatures & {$[127]$} \\
\hline 7 & climate & prec30_max & highest precipitation value (wettest month) & [127] \\
\hline 8 & climate & prec30_min & lowest precipitation value (driest month) & {$[127]$} \\
\hline 9 & climate & prec30_std & standard deviation of the precipitation & {$[127]$} \\
\hline 10 & climate & prec30_sum & total annual precipitation & {$[127]$} \\
\hline 11 & environment & glc_raw2 & vegetation derived from the near-infrared $(0.78-0.89 \mu \mathrm{m})$ wavelength of the SPOT4 satellite & [128] \\
\hline 12 & environment & glc_raw3 & vegetation derived from the red $(0.61-0.68 \mu \mathrm{m})$ wavelength of the SPOT4 satellite & [128] \\
\hline 13 & environment & bare_4x4 & percentage of bare ground (MODIS) & [129] \\
\hline 14 & environment & herb_4x4 & percentage of herbaceous ground cover (MODIS) & [130] \\
\hline 15 & environment & tree_ $4 \times 4$ & percentage of woody vegetation (MODIS) & [131] \\
\hline 16 & altitude & srtm_c_ln_3x3 & elevational contrast calculated from the SRTM30 data set using a $3 \times 3$ moving window & [132] \\
\hline 17 & altitude & srtm_v_In_9x9 & elevational variance calculated from the SRTM30 data set using a 9x9 moving window & [132] \\
\hline 18 & distance & hydro_buf_af & distance to nearest river & [133] \\
\hline
\end{tabular}

Provided are: number, category assignment, parameter acronym, description of the parameter and the source of the original data.

ENMs were calculated considering 1) all presence data in order to determine the potential distribution of the family Odontobatrachidae in Upper Guinea (OTUcomb) and 2) to those localities assigned to a particular OTU, in order to determine the potential distribution of each molecular lineage. The algorithm and parameters disregard biotic factors limiting species distribution [59]. Consequently, models detected areas that are inaccessible due to geographical immigration barriers or competitive exclusion once a niche is already occupied. Such results should be evaluated with caution when discussing the potential distribution. Details of the jackknifing tests of variable importance to the calculated ENMs are provided in Additional file 14.

\section{Conservation status}

Following IUCN Red List criteria the geographic range, assessed as the Extent of Occurrence (EOO) and the Area of Occupancy (AOO), are among the crucial criteria for classifying a taxon as "Critically Endangered", "Endangered" or "Vulnerable". While EOO is roughly defined as the least space contained between all known points and often measured by a minimum convex polygon, AOO refers to the area within the species EOO which is occupied by a taxon (herein OTU) on a $4 \mathrm{~km}^{2}$ grid. EOO and $\mathrm{AOO}$ were calculated for all recognised OTUs using GeoCAT [126] and according to the IUCN regulation the higher of these two categories is crucial for the final species classification to assess its risk of global extinction [87].

\section{Availability of supporting data}

The data sets supporting the results of this article are included within the article (and its additional files). Gene sequences obtained in the course of this study have been deposited in GenBank under accessions KP005071KP005450 (see also Additional file 11) and are available in the TreeBASE repository, under http://purl.org/phylo/ treebase/phylows/study/TB2:S17293.

\section{Additional files}

Additional file 1: Relationships (expanded concatenated tree) and geographical distribution of Odontobatrachus OTUs.

Additional file 2: Number of total clusters/OTUs identified using Speciesldentifier at different cut-off thresholds.

Additional file 3: Tree showing results of species delimitation approaches (GMYC and cluster algorithm in SpeciesIdentifier.

Additional file 4: GMYC model results under different tree priors and clock models.

Additional file 5: Dating results of splits between Odontobatrachus OTUs.

Additional file 6: ENM training results of all five OTUs and OTUcomb (OTU1-4 + natator).

Additional file 7: Summary of parameters and their contribution to the ENM approach.

Additional file 8: Hypothetical scenario of dispersal and speciation in the family Odontobatrachidae in the Upper Guinean forest block, West Africa.

Additional file 9: Map of protected areas in Upper Guinean forests, West Africa, and distribution of Odontobatrachus OTUs. 


\section{Additional file 10: Mountainous elevations in Upper Guinean forests inhabited by Odontobatrachidae.}

Additional file 11: Summary of voucher specimens, and GenBank accession numbers included in the present study.

Additional file 12: Phylogenetic tree of Odontobatrachus OTUs under minimum and maximum partitioning schemes.

Additional file 13: Single gene trees of Odontobatrachus OTUs. Additional file 14: Results of the jackknifing tests.

\section{Abbreviations}

12S: 12S rRNA; 16S: 16S rRNA; cytb: Cytochrome b; RAG1: Recombinase activating protein 1; SIA: Seventh-in-absentia; BDNF: Brain-derived neurotrophic factor; bp: Base pairs; OTU: Operational taxonomic units; BI: Bayesian inference; ML: Maximum likelihood; BS: Bootstrap support; PP: Posterior probability; BIC: Bayesian information criterion; GTR: General time reversible model; HKY: Hasegawa-Kishino-Yano 85 model; JC: Jukes and Cantor 1969 model; K80: Kimura 1980 model; TIM: Transition model; TPM2uf: Three-parameter model with unequal base frequencies; TrNef: Tamura and Nei 1983 model with equal frequencies; G: Gamma distribution; I: Proportion of invariable sites; ENM: Environmental niche modelling; ROC: Receiver operating characteristic; AUC: Area under the curve; min: Minimum; max: Maximum; SD: Standard deviation; N: Sample size; BM: Natural History Museum, London; MHNG: Natural History Museum, Geneva; ZFMK: Zoologisches Forschungsmuseum Alexander Koenig, Bonn; ZMB: Museum für Naturkunde Berlin; FP: Freetown peninsula population; IL: Inland population; Mt: Mount; IUCN: International union for conservation of nature; RL: Red list; EOO: Extent of occurrence; AOO: Area of occupancy.

\section{Competing interests}

The authors declare that they have no competing interests.

\section{Authors' contributions}

MFB, MOR, AS designed the study. MFB, JP, MOR participated in the collection of samples. MFB and AS generated sequence data and performed molecular analyses. JP generated environmental niche models. MFB and MOR wrote the paper. All authors read and approved the final manuscript.

\section{Acknowledgments}

We thank all respective West African authorities for research, access, and collection and export permits, as well as our many guides and field assistants for their courageous help in finding frogs. The study was partly funded by Rio Tinto and Rudolf G. Arndt (Galloway). Neither the company nor R.G. Arndt had taken any influence on data collection, analyses or interpretation; the authors thus declare no conflict of interest. Stephan Nylinder (Swedish Museum of Natural History, Stockholm) was confronted with difficulties in dating approaches and gave invaluable advices leading to a passable solution. We would like to thank the editor, as well as Dan Portik and a second anonymous reviewer for valuable comments which improved our manuscript. We are indebted to David C. Blackburn (CAS) for a thorough linguistic revision of our work. Additional samples have been provided by Patrick Joël Adeba, M. Alhassane Bangoura, Christian Brede, Joseph Doumbia, Nono L. Gonwouo, Annika Hillers, Mareike Hirschfeld, N'Goran Germain Kouamé, Joachim Nopper, and Laura Sandberger. MFB thanks Rudolf G. Arndt, for his trust in young scientists.

\section{Author details}

Museum für Naturkunde Berlin, Leibniz Institute for Evolution and Biodiversity Science, Invalidenstrasse 43, D-10115 Berlin, Germany. ${ }^{2}$ Department of Herpetology and Ichthyology, Natural History Museum of Geneva, CP 6434, 1211, Geneva 6, Switzerland.

Received: 1 October 2014 Accepted: 31 March 2015

Published online: 19 April 2015

\section{References}

1. Toews DPL, Irwin DE. Cryptic speciation in a Holarctic passerine revealed by genetic and bioacoustic analyses. Mol Ecol. 2008;17:2691-705.
2. Channing A, Schmitz A, Burger M, Kielgast J. A molecular phylogeny of African Dainty Frogs, with the description of four new species (Anura: Pyxicephalidae: Cacosternum). Zootaxa. 2013;3701:518-50.

3. Wilkins MR, Seddon N, Safran RJ. Evolutionary divergence in acoustic signals: causes and consequences. Trends Ecol Evol. 2013;28:156-66.

4. Umina PA, Hoffman AA, Weeks AR. Biology, ecology and control of the Penthaleus species complex (Acari: Penthaleidae). Exp Appl Acarol. 2004;34:211-37.

5. Souto RP, Fernandes O, Macedo AM, Campbell DA, Zingales B. DNA markers define two major phylogenetic lineages of Trypanosoma cruzi. Mol Biochem Parasitol. 1996;83:141-52

6. Zhang YZ, Si SL, Zheng JT, Li HL, Fang Y, Zhu CD, et al. DNA barcoding of endoparasitoid wasps in the genus Anicetus reveals high levels of host specificity (Hymenoptera: Encyrtidae). Biol Control. 2011;58:182-91.

7. Daugherty $\mathrm{CH}$, Cree A, Hay JM, Thompson MB. Neglected taxonomy and continuing extinctions of tuatara (Sphenodon). Nature. 1990;347:177-9.

8. Ravaoarimanana IB, Tiedemann R, Montagnon D, Rumpler Y. Molecular and cytogenetic evidence for cryptic speciation within a rare endemic Malagasy lemur, the Northern Sportive Lemur (Lepilemur septentrionalis). Mol Phyl Evol. 2004;31:440-8.

9. McLeod DS. Of Least Concern? Systematics of a cryptic species complex: Limnonectes kuhlii (Amphibia; Anura: Dicroglossidae). Mol Phyl Evol. 2010;56:991-1000

10. Bickford D, Lohman DJ, Navjot SS, Ng PKL, Meier R, Winker K, et al. Cryptic species as a window on diversity and conservation. Trends Ecol Evol. 2007;22:148-55.

11. Dexter KG, Pennington TD, Cunningham CW. Using DNA to assess errors in tropical tree identifications: How often are ecologists wrong and when does it matter? Ecol Monogr. 2010;80:267-86.

12. Conn PB, McClintock BT, Cameron MF, Johnson DS, Moreland EE, Boveng $\mathrm{PL}$. Accommodating species identification errors in transect surveys. Ecology. 2013;94:2607-18.

13. Beerkircher L, Arocha F, Barse A, Prince E, Restrepo V, Serafy J, et al. Effects of species misidentification on population assessment of overfished white marlin Tetrapturus albidus and roundscale spearfish T. georgii. Endang Species Res. 2009;9:81-90.

14. Purvis A, Agapow P-M, Gittleman JL, Mace GM. Nonrandom extinction and the loss of evolutionary history. Science. 2000;288:328-30.

15. Mayer F, Dietz C, Kiefer A. Molecular species identification boosts bat diversity. Front Zool. 2007:4:4.

16. Angulo A, Reichle S. Acoustic signals, species diagnosis, and species concepts: the case of new cryptic species of Leptodactylus (Amphibia, Anura, Leptodactylidae) from the Chapare region, Bolivia. Zool J Linn Soc. 2008;152:59-77.

17. Pfenninger M, Schwenk K. Cryptic animal species are homogeneously distributed among taxa and biogeographical regions. BMC Evol Biol. 2007;7:121.

18. Steenkamp ET, Wingfield BD, Desjardins AE, Marasas WFO, Wingfield MJ. Cryptic speciation in Fusarium subglutinans. Mycologia. 2002;94:1032-43.

19. Shaw AJ. Molecular phylogeography and cryptic speciation in the mosses, Mielichhoferia elongate and M. mielichhoferiana (Bryaceae). Mol Ecol. 2000;9:595-608.

20. Blair CP, Abrahamson WG, Jackman JA, Tyrrell L. Cryptic speciation and host-race formation in a purportedly generalist tumbling flower beetle. Evolution. 2005;59:304-16.

21. Mayer F, von Helversen O. Cryptic diversity in European bats. Proc Royal Soc Ser B Biol Sci. 2001;268:1825-32

22. Townsend TM, Vieites DR, Glaw F, Vences M. Testing species-level diversification hypotheses in Madagascar: the case of microendemic Brookesia leaf chameleons. Syst Biol. 2009;58:461-656.

23. Quattro JM, Stoner DS, Driggers WB, Anderson CA, Priede KA, Hoppmann EC, et al. Evidence of cryptic speciation within hammerhead sharks (genus Sphyrna). Mar Biol. 2006;148:1143-55.

24. Yoder AD, Rasoloarison RM, Goodman SM, Irwin JA, Atsalis S, Ravosa MJ, et al. Remarkable species diversity in Malagasy mouse lemurs (Primates, Microcebus). Proc Natl Acad Sci U S A. 2000;97:11325-30.

25. Brown DM, Brenneman RA, Georgiadis NJ, Koepfli K, Pollinger JP, Mila B, et al. Extensive population genetic structure in the giraffe. BMC Biol. 2007;5:57.

26. Roca AL, Georgiadis N, Pecon-Slattery J, O'Brien SJ. Genetic evidence for two species of elephant in Africa. Science. 2001;293:1473-7. 
27. Stuart BL, Inger RF, Voris HK. High level of cryptic species diversity revealed by sympatric lineages of Southeast Asian forest frogs. Biol Lett. 2006;2:470-4.

28. Kieswetter CM, Schneider CJ. Phylogeography in the northern Andes: Complex history and cryptic diversity in a cloud forest frog, Pristimantis w-nigrum (Craugastoridae). Mol Phyl Evol. 2013;69:417-29.

29. Fouquet A, Gilles A, Vences M, Marty C, Blanc M, Gemmell NJ. Underestimation of species richness in Neotropical frogs revealed by mtDNA analyses. PLoS One. 2007;2:e1109.

30. Vieites DR, Wollenberg KC, Andreone F, Köhler J, Glaw F, Vences M. Vast underestimation of Madagascar's biodiversity evidenced by an integrative amphibian inventory. Proc Natl Acad Sci U S A. 2009;106:8267-72.

31. Cherry LM, Case SM, Wilson AC. Frog perspective on the morphological difference between humans and chimpanzees. Science. 1978;200:209-11.

32. Highton R. Speciation in eastern North American salamanders of the genus Plethodon. Annu Rev Ecol Evol Syst. 1995;26:579-600

33. Barej MF, Schmitz A, Günther R, Loader SP, Mahlow K, Rödel M-O. The first endemic West African vertebrate family - a new anuran family highlighting the uniqueness of the Upper Guinean biodiversity hotspot. Front Zool. 2014;11:8.

34. Boulenger GA. Descriptions of new West-African frogs of the genera Petropedetes and Bulua. Ann Mag Nat Hist. 1905:15:281-3.

35. Guibé J, Lamotte M. La réserve naturelle intégrale du Mont Nimba. XII. Batraciens (sauf Arthroleptis, Phrynobatrachus et Hyperolius). Mém Inst fond Afr noire. 1958:53:241-73.

36. Rödel M-O. The amphibians of Mont Sangbé National Park, Ivory Coast. Salamandra. 2003;39:91-110.

37. Rödel M-O, Bangoura MA, Böhme W. The amphibians of south-eastern Republic of Guinea (Amphibia: Gymnophiona, Anura). Herpetozoa. 2004;17:99-118.

38. Hillers A, Rödel M-O. The amphibians of three national forests in Liberia, West Africa. Salamandra. 2007:43:1-10

39. Hillers A, Loua N, Rödel M-O. A preliminary assessment of the amphibians of the Fouta Djallon, Guinea, West Africa. Salamandra. 2008;44:113-22.

40. Fahr J, Vierhaus $H$, Hutterer $\mathrm{R}$, Kock D. A revision of the Rhinolophus maclaudi species group with the description of a new species from West Africa (Chiroptera: Rhinolophidae). Myotis. 2002;40:95-126.

41. Monadjem A, Richards L, Taylor PJ, Stoffberg S. High diversity of pipistrelloid bats (Vespertilionidae: Hypsugo, Neoromicia, and Pipistrellus) in a West African rainforest with the description of a new species. Zool J Linn Soc. 2013:167:191-207.

42. Monadjem A, Richards L, Taylor PJ, Denys C, Dower A, Stoffberg S. Diversity of Hipposideridae in the Mount Nimba massif, West Africa, and the taxonomic status of Hipposideros lamottei. Acta Chiropterologica. 2013;15:341-52.

43. Nicolas V, Bryja J, Akpatou B, Konecny A, Lecompte E, Colyn M, et al. Comparative phylogeography of two sibling species of forest-dwelling rodent (Praomys rostratus and P. tullbergi) in West Africa: different reactions to past forest fragmentation. Mol Ecol. 2008;17:5118-34.

44. Rödel M-O, Bangoura MA. A conservation assessment of amphibians in the Forêt Classée du Pic de Fon, Simandou Range, southeastern Republic of Guinea, with the description of a new Amnirana species (Amphibia Anura Ranidae). Trop Zool. 2004;17:201-32.

45. Barej MF, Rödel M-O, Loader SP, Menegon M, Gonwouo NL, Penner J, et al. Light shines through the spindrift - phylogeny of African Torrent Frogs (Amphibia, Anura, Petropedetidae). Mol Phyl Evol. 2014;71:261-73.

46. Elmer KR, Dávila JA, Lougheed SC. Cryptic diversity and deep divergence in an upper Amazonian leaflitter frog, Eleutherodactylus ockendeni. BMC Evol Biol. 2007:7:247.

47. Jörger KM, Schrödl M. How to describe a cryptic species? Practical challenges of molecular taxonomy. Front Zool. 2013;10:59.

48. Vences M, Thomas M, van der Meijden A, Chiari Y, Vieites DR. Comparative performance of the $16 \mathrm{~S}$ rRNA gene in DNA barcoding of amphibians. Front Zool. 2005;2:1-12.

49. Camargo A, De Sá RO, Heyer WR. Phylogenetic analyses of mtDNA sequences reveal three cryptic lineages in the widespread neotropical frog Leptodactylus fuscus (Schneider, 1799) (Anura, Leptodactylidae). Biol J Linn Soc. 2006;87:325-41.

50. Barej MF, Rödel M-O, Gonwouo NL, Pauwels OSG, Böhme W, Schmitz A Review of the genus Petropedetes Reichenow, 1874 in Central Africa with the description of three new species (Amphibia: Anura: Petropedetidae). Zootaxa. 2010;2340:1-49.
51. Barej MF, Schmitz A, Menegon M, Hillers A, Hinkel H, Böhme W, et al. Dusted off - the African Amietophrynus superciliaris-species complex of giant toads. Zootaxa. 2011;2772:1-32.

52. Rödel M-O, Barej MF, Hillers A, Leaché AD, Kouamé NG, Ofori-Boateng C, et al. The genus Astylosternus in the Upper Guinea rainforests, West Africa, with the description of a new species (Amphibia: Anura: Arthroleptidae). Zootaxa. 2012;3245:1-29.

53. Channing A, Hillers A, Lötters S, Rödel M-O, Schick S, Conradie W, et al. Taxonomy of the super-cryptic Hyperolius nasutus group of long reed frogs of Africa (Anura: Hyperoliidae), with descriptions of six new species. Zootaxa. 2013;3620:301-50

54. Ye S, Huang H, Zheng R, Zhang J, Yang G, Xu S. Phylogeographic analyses strongly suggest cryptic speciation in the giant spiny frog (Dicroglossidae: Paa spinosa) and interspecies hybridization in Paa. PLoS One. 2013;8:1-9.

55. Wiens JJ, Penkrot TA. Delimiting species using DNA and morphological variation and discordant species limits in spiny lizards (Sceloporus). Syst Biol. 2002:51:69-91.

56. Funk DJ, Omland KE. Species-level paraphyly and polyphyly: Frequency, causes, and consequences, with insights from animal mitochondrial DNA. Annu Rev Ecol Evol Syst. 2003;34:397-423.

57. Irissari I, San Mauro D, Abascal F, Ohler A, Vences M, Zardoya R. The origin of modern frogs (Neobatrachia) was accompanied by acceleration in mitochondrial and nuclear substitution rates. BMC Genomics. 2012;13:e626.

58. Penner J, Wegmann M, Hillers A, Schmidt M, Rödel M-O. A hotspot revisited - a biogeographical analysis of West African amphibians. Divers Distrib. 2011;17:1077-88.

59. Wisz MS, Pottier J, Kissling WD, Pellissier L, Lenoir J, Damgaard CF, et al. The role of biotic interactions in shaping distributions and realised assemblages of species: implications for species distribution modelling. Biol Rev. 2013:88:15-30.

60. Nichol JE. Geomorphological evidence and Pleistocene refugia in Africa. Geophys J Roy Astron Soc. 1999;165:79-89.

61. DeMenocal PB. African climate change and faunal evolution during the Pliocene-Pleistocene. Earth Planet Sci Lett. 2004;220:3-24.

62. Trauth MH, Larrasoaña JC, Mudelsee M. Trends, rhythms and events in Plio-Pleistocene African climate. Quat Sci Rev. 2009;28:399-411.

63. Mayr E, O'Hara EJ. The biogeographic evidence supporting the Pleistocene forest refuge hypothesis. Evolution. 1986:40:55-67.

64. Fjeldså J, Lovett JC. Geographical patterns of old and young species in African forest biota: the significance of specific montane areas as evolutionary centres. Biodiver Conserv. 1997;6:323-44.

65. Maley J. The impact of arid phases on the African rain forest through geological history. In: Weber W, White L, Vedder A, Naughton-Treves L, editors. African rain forest ecology and conservation. Connecticut: Yale University Press; 2001. p. 8-87.

66. Maley J. Fragmentation de la forêt dense humide africaine et extension des biotopes montagnards ou Quartenaire récent: nouvelles données polliniques et chronologiques. Implications paléoclimatiques et biogéographiques. Palaeoecol Afr. 1987:18:307-34.

67. Jacquet F, Nicolas V, Colyn M, Kadjo B, Hutterer R, Decher J, et al. Forest refugia and riverine barriers promote diversification in the West African pygmy shrew (Crocidura obscurior complex, Soricomorpha). Zool Scr. 2014:43:131-48

68. Leal ME. Microrefugia, small scale ice age forest remnants. Syst Geogr. 2001;71:1073-7

69. Angel F. Description d'un nouvelle Amphibien anoure, ovo-vivipare, de la Haute Guinée Française. (Materiaux de la Mission Lamotte, au Mont-Nimba). 2e note. Bull Mus Nat Hist Nat, Ser 2. 1943;15:167-9.

70. Brosset A. Chiroptères d'altitude du Mont Nimba (Guinée). Description d'une espèce nouvelle, Hipposideros lamottei. Mammalia. 1984;48:545-55.

71. Porembski S, Barthlott W, Dörrstock S, Biedinger N. Vegetation of rock outcrops in Guinea: granite inselbergs, sandstone table mountains and ferricretes - remarks on species numbers and endemism. Flora. 1994;189:315-26.

72. Porembski S, Biedinger N, Dörrstock S. Zur Vegetation Guineas unter besonderer Berücksichtigung der Inselbergflora. Nat Mus. 1995;125:143-54.

73. Sosef MSM. Studies in Begoniaceae V. Refuge Begonias. Taxonomy, phylogeny and historical biogeography of Begonia sect. Loasibegonia and sect. Scutobegonia in relation to glacial rain forest refuges in Africa. Wageningen: Agricultural University Papers; 1994.

74. deMenocal PB. Plio-Pleistocene African Climate. Science. 1995;270:53-9. 
75. Dupont LM, Jahns S, Marret F, Ning S. Vegetation change in equatorial West Africa: time-slices for the last $150 \mathrm{ka}$. Palaeogeogr Palaeoclimatol Palaeoecol. 2000;155:95-122.

76. Lambin EF, Geist HJ. Regional differences in tropical deforestation. Environ Sci Technol. 2003;45:22-36.

77. Myers N, Mittermeier RA, Mittermeier CG, DaFonseca GAB, Kent J. Biodiversity hotspots for conservation priorities. Nature. 2000;403:853-8.

78. Rudel T, Roper J. Forest fragmentation in the humid tropics: a cross-national analysis. Singapore J Trop Geogr. 1997;18:99-109.

79. Brooks TM, Mittermeier RA, Mittermeier CG, da Fonseca GAB, Rylands AB Konstant WR, et al. Habitat loss and extinction in the hotspots of biodiversity. Conserv Biol. 2002;16:909-23.

80. Geist HJ, Lambin EF. Proximate causes and underlying driving forces of tropical deforestation. Bioscience. 2002;52:143-50.

81. FAO. Global forest resources assessment 2005. Progress towards sustainable forest management. FAO Forestry Paper $N^{\circ} 147$. Rome: Food and Agriculture Organization of the United Nations; 2006.

82. Hillers $A$, Veith $M$, Rödel M-O. Effects of forest fragmentation and habitat degradation on West African leaf-litter frogs. Conserv Biol. 2008;22:762-72.

83. Brink AB, Eva HD. Monitoring 25 years of land cover change dynamics in Africa: A sample based remote sensing approach. Appl Geogr. 2009;29:501-12.

84. DeFries RS, Rudel T, Uriarte M, Hansen M. Deforestation driven by urban population growth and agricultural trade in the twenty-first century. Nat Geosci. 2010;3:178-81.

85. Edwards DP, Sloan S, Weng L, Dirks P, Sayer J, Laurance WF. Mining and the African environment. Conserv Lett. 2014;7:302-11.

86. Cushman SA. Effects of habitat loss and fragmentation on amphibians: a review and prospectus. Biol Conserv. 2006;128:231-40.

87. IUCN. The IUCN Red List of Threatened Species. Version 2014.2 [http://www.iucnredlist.org]

88. Moritz C. Defining 'Evolutionary Significant Units' for conservation. Trends Ecol Evol. 1996;9:373-5

89. Moritz C. Strategies to protect biological diversity and the evolutionary processes that sustain it. Syst Biol. 2002:51:238-54.

90. Fraser DJ, Bernatchez L. Adaptive evolutionary conservation: towards a unified concept for defining conservation units. Mol Ecol. 2001;10:2741-52.

91. Brugiere D, Kormos R. Review of the protected area network in Guinea, West Africa, and recommendations for new sites for biodiversity conservation. Biodiv Conserv. 2009:18:847-68.

92. Hillers A, Loua N-S, Rödel M-O. Assessment of the distribution and conservation status of the viviparous toad Nimbaphrynoides occidentalis on Monts Nimba, Guinea. Endang Spec Res. 2008;5:13-9.

93. Benson DA, Cavanaugh M, Clark K, Karsch-Mizrachi I, Lipman DJ, Ostell J, et al. GenBank. Nucleic Acids Res. 2013;41:D36-42.

94. Hall TA. BioEdit: a user-friendly biological sequence alignment editor and analysis program for Windows 95/98/NT. Nucleic Acids Symp Ser. 1999:41:95-8.

95. Thompson JD, Gibson TJ, Plewniak F, Jeanmougin F, Higgins DG. The ClustalX windows interface: flexible strategies for multiple sequence alignment aided by quality analysis tools. Nucleic Acids Res. 1997;24:4876-82.

96. Abascal F, Zardoya R, Telford MJ. TranslatorX: multiple alignment of nucleotide sequences guided by amino acid translations. Nucleic Acids Res. 2010;38:W7-13.

97. Huelsenbeck JP, Ronquist F. MRBAYES: Bayesian inference of phylogenetic trees. Bioinformatics. 2001;17:754-5.

98. Ronquist F, Teslenkol M, van der Mark P, Ayres DL, Darling A, Höhna S, et al. MrBayes 3.2: Efficient Bayesian Phylogenetic Inference and model choice across a large model space. Syst Biol. 2012;61:539-42

99. Stamatakis A. RAxML-VI-HPC: Maximum Likelihood-based phylogenetic analyses with thousands of taxa and Mixed Models. Bioinformatics. 2006;22:2688-90.

100. Stamatakis A, Blagojevic F, Nikolopoulos D, Antonopoulos C. Exploring new search algorithms and hardware for phylogenetics: RAxML meets the IBM Cell. J VLSI Sig Proc Sys. 2007;48:271-86.

101. Lanfear R, Calcott B, Ho SYW, Guindon S. PartitionFinder: combined selection of partitioning schemes and substitution models for phylogenetic analyses. Mol Biol Evol. 2012;29:1695-701.

102. Darriba D, Taboada GL, Doallo R, Posada D. jModelTest 2: more models, new heuristics and parallel computing. Nat Methods. 2012;9:772.
103. Rambaut A, Drummond AJ. Tracer v1.6. [http://beast.bio.ed.ac.uk/Tracer].

104. Swofford DL. PAUP*. Phylogenetic Analysis Using Parsimony ( ${ }^{*}$ and Other Methods). Version 4.0b10. Massachusetts: Sinauer Associates, Sunderland; 2002

105. Clement M, Posada D, Crandall KA. TCS: a computer program to estimate gene genealogies. Mol Ecol. 2000;9:1657-9.

106. Heled J, Drummond AJ. Bayesian inference of species trees from multilocus data. Mol Biol Evol. 2010;27:570-80.

107. Drummond AJ, Suchard MA, Xie D, Rambaut A. Bayesian phylogenetics with BEAUti and the BEAST 1.7. Mol Biol Evol. 2012;29:1969-73.

108. Rambaut A. FigTree version 1.4.0. [http://tree.bio.ed.ac.uk/software/figtree/]

109. Meier R, Kwong S, Vaidya G, Ng PKL. DNA barcoding and taxonomy in Diptera: a tale of high intraspecific variability and low identification success. Syst Biol. 2006:55:715-28.

110. Pons J, Barraclough TG, Gomez-Zurita J, Cardoso A, Durans DP, Hazell S, et al. Sequence-based species delimitation for the DNA taxonomy of undescribed insects. Syst Biol. 2006;55:595-609.

111. Fontaneto D, Herniou E, Boschetti C, Caprioli M, Melone G, Ricci C, et al. Independently evolving species in asexual bdelloid rotifers. PLoS Biol. 2007:5:e87.

112. Fujisawa T, Barraclough TG. Delimiting species using single-locus data and the Generalized Mixed Yule Coalescent approach: A revised method and evaluation on simulated data sets. Syst Biol. 2013;62:707-24

113. Drummond AJ, Rambaut A. BEAST: Bayesian evolutionary analysis by sampling trees. BMC Evol Biol. 2007:7:e214.

114. Gehring P-S, Tolley KA, Eckhard FS, Townsend TM, Ziegler T, Ratsoavina F, et al. Hiding deep in the trees: discovery of divergent mitochondrial lineages in Malagasy chameleons of the Calumma nasutum group. Ecol Evol. 2012;2:1468-79.

115. Kingman JFC. The coalescent. Stoch Processes Appl. 1982;13:235-48.

116. Drummond AJ, Ho SY, Phillips MJ, Rambaut A. Relaxed phylogenetics and dating with confidence. PLOS Biol. 2006:4:e88.

117. Miralles A, Carranza S. Systematics and biogeography of the Neotropical genus Mabuya, with special emphasis on the Amazonian skink Mabuya nigropunctata (Reptilia, Scincidae). Mol Phyl Evol. 2010;54:857-69.

118. Stöck M, Dufresnes C, Litvinchuk SN, Lymberakis P, Biollay S, Berroneau M, et al. Cryptic diversity among Western Palearctic tree frogs: Postglacial range expansion, range limits, and secondary contacts of three European tree frog lineages (Hyla arborea group). Mol Phyl Evol. 2012;65:1-9.

119. Zhou W, Yan F, Fu J, Wu S, Murphy RW, Che J, et al. River islands, refugia and genetic structuring in the endemic brown frog Rana kukunoris (Anura Ranidae) of the Qinghai-Tibetan Plateau. Mol Ecol. 2013;22:130-42.

120. Phillips SJ, Dudík M, Schapire RE. A maximum entropy approach to

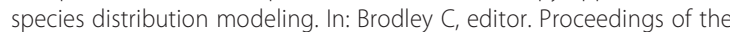
Twenty-First International Conference on Machine Learning. New York: ACM Press; 2004. p. 655-62.

121. Phillips SJ, Anderson RP, Schapire RE. Maximum entropy modeling of species geographic distributions. Ecol Model. 2006;190:231-59.

122. Phillips SJ, Dudík M. Modeling of species distributions with Maxent: new extensions and a comprehensive evaluation. Ecography. 2008;31:161-75.

123. Elith J, Graham CH, Anderson RP, Dudík M, Ferrier S, Guisan A, et al. Novel methods improve prediction of species' distributions from occurrence data. Ecography. 2006;29:129-51.

124. Heikkinen RK, Marmion M, Luoto M. Does the interpolation accuracy of species distribution models come at the expense of transferability? Ecography. 2011;35:276-88.

125. Penner J, Adum GB, McElroy MT, Doherty-Bone T, Hirschfeld M, Sandberger $L$, et al. West Africa - A safe haven for frogs? A sub-continental assessment of the chytrid fungus (Batrachochytrium dendrobatidis). PLoS One. 2013:8:e56236.

126. Bachman S, Moat J, Hill A, de la Torre J, Scott B. Supporting Red List threat assessments with GeoCAT: geospatial conservation assessment tool. ZooKeys. 2011;150:117-26.

127. Hijmans RJ, Cameron SE, Parra JL, Jones PG, Jarvis A. Very high resolution interpolated climate surfaces for global land areas. Int J Climatol. 2005:25:1965-78

128. Arnaud M, Leroy M. SPOT 4: a new generation of SPOT satellites. ISPRS J Photogramm Remote Sens. 1991:46:205-15.

129. Hansen M, DeFries R, Townshend JR, Carroll M, Dimiceli C, Sohlberg R. Vegetation Continuous Fields MOD44B, 2001 Percent bare ground cover, Collection 3. Maryland: University of Maryland, College Park; 2003. 
130. Hansen M, DeFries R, Townshend JR, Carroll M, Dimiceli C, Sohlberg R. Vegetation Continuous Fields MOD44B, 2001 Percent herbaceous ground cover, Collection 3. Maryland: University of Maryland, College Park; 2003.

131. Hansen M, DeFries R, Townshend JR, Carroll M, Dimiceli C, Sohlberg R. Vegetation Continuous Fields MOD44B, 2001 Percent tree cover, Collection 3. Maryland: University of Maryland, College Park; 2003.

132. Farr TG, Rosen PA, Caro E, Crippen R, Duren R, Hensley S, et al. The shuttle radar topography mission. Rev Geophys. 2007:45:1-33.

133. Gschweng M, Kalko EKV, Berthold P, Fiedler W, Fahr J. Multi-temporal distribution modelling with satellite tracking data: predicting responses of a long-distance migrant to changing environmental conditions. J Appl Ecol. 2012;49:803-13.

\section{Submit your next manuscript to BioMed Central and take full advantage of:}

- Convenient online submission

- Thorough peer review

- No space constraints or color figure charges

- Immediate publication on acceptance

- Inclusion in PubMed, CAS, Scopus and Google Scholar

- Research which is freely available for redistribution 